\title{
Crescimento da mandioca e plantas daninhas em resposta à adubação fosfatada
}

\author{
Gustavo Antônio Mendes Pereiral, Vinícius Teixeira Lemos ${ }^{1}$, José Barbosa dos Santos², Evander Alves Ferreira ${ }^{3}$, \\ Daniel Valadão Silva ${ }^{4}$, Maxwel Coura de Oliveiral ${ }^{1}$ Claubert Wagner Guimarães de Menezes ${ }^{1}$
}

\begin{abstract}
RESUMO
Os fertilizantes podem ser usados para alterar as relações de competitividade, de modo a favorecer as espécies cultivadas, desde que as espécies competidoras apresentem respostas diferenciadas à aplicação de nutrientes. Por essas razões, objetivou-se, com este trabalho, avaliar o crescimento do picão preto (Bidens pilosa L.), da braquiária (Brachiaria decumbens Stapf) e da mandioca (Manihot esculenta Crantz), cultivados sob diferentes quantidades de fósforo fornecidas no plantio. Para isso, foi conduzido experimento em casa de vegetação, em arranjo fatorial 3x4, sendo o primeiro fator constituído pelas espécies estudadas, combinadas com quatro níveis de adubação fosfatadas $\left(0,80,800\right.$ e $4.000 \mathrm{~kg} \mathrm{ha}^{-1}$ de $\left.\mathrm{P}_{2} \mathrm{O}_{5}\right)$, no delineamento em blocos casualizados, com cinco repetições. A aplicação do fertilizante fosfatado promoveu maior crescimento das espécies avaliadas, sendo que a mandioca apresentou maior crescimento da parte área com o aumento da disponibilidade de fósforo. De maneira geral, as plantas daninhas apresentaram maiores respostas às menores doses de fósforo.
\end{abstract}

Palavras-chave: Manihot esculenta Crantz, Bidens pilosa L., Brachiaria decumbens Stapf, fósforo.

\section{ABSTRACT}

\section{Growth of cassava and weed in response to phosphate fertilizer}

Fertilizers may be used to change the competitive relations, favoring the crop species, providing the competing species have different responses to the nutrient application. Thus, the aim of this study was to evaluate the growth of Cassava plant, Bidens pilosa L. and Brachiaria decumbens Stapf, as a function of the amount of P supplied at planting. The experiment was conducted in a greenhouse and the, treatments were arranged in a $3 \mathrm{x} 4$ factorial, involving the three species studied and four levels of phosphate fertilization (absence of $\mathrm{P}_{2} \mathrm{O}_{5}, 80 \mathrm{~kg} \mathrm{ha}^{-1}, 800 \mathrm{~kg}^{-}$ha${ }^{1}$ and $4000 \mathrm{~kg} \mathrm{ha}^{-1} \mathrm{P}_{2} \mathrm{O}_{5}$, equivalent to $0,1,10$ and 50 times the phosphorus dose recommended, respectively). A randomized block design was used, with five replications. The application of phosphate fertilizer promoted larger growth of the species evaluated, and cassava had higher growth of the shoot with the increased availability of phosphorus. In general, weeds showed higher responses to lower doses of phosphorus.

Key words: Manihot esculenta Crantz, Bidens pilosa L., Brachiaria decumbens Stapf, phosphorus.

Recebido para publicação em 09/03/2012 e aprovado em 30/07/2012.

${ }^{1}$ Engenheiro-Agrônomo. Mestrando do Departamento de Agronomia Universidade Federal do Jequitinhonha e Mucuri, Rodovia MGT 367, Km 583, 5000, Alto da Jacuba, 39100000, Diamantina, Minas Gerais, Brasil. gustavogamp@hotmail.com; Brasil. lemosvt@yahoo.com.br; maxwelco@gmail.com; claubertmenezes@yahoo.com.br

${ }^{2}$ Engenheiro-Agrônomo, DS. Departamento de Agronomia, Universidade Federal do Jequitinhonha e Mucuri, Rodovia MGT 367, Km 583, 5000, 39100-000, Alto da Jacuba, Diamantina, Minas Gerais, Brasil. jbarbosasantos@yahoo.com.br

${ }^{3}$ Engenheiro-Agrônomo, DS. Pós-doutorando do Departamento de Agronomia, Universidade Federal do Jequitinhonha e Mucuri, Rodovia MGT 367, Km 583, 5000, Alto da Jacuba, 39100-000, Diamantina, Minas Gerais, Brasil. evanderalves@yahoo.com.br

${ }^{4}$ Engenheiro-Agrônomo, MSc. Doutorando do Departamento de Fitotecnia, Universidade Federal de Viçosa, Campus Viçosa, Avenida Peter Henry Rolfs, s/n, 36570-000, Viçosa, 36570-000, Minas Gerais, Brasil. danielvaladaos@yahoo.com.br (autor para correspondência). 


\section{INTRODUÇÃO}

Em todo o território brasileiro, são encontradas áreas cultivadas com a mandioca (Manihot esculenta Crantz), sendo gerados cerca de dois milhões de empregos na sua agroindústria (IBGE, 2011). A produção é destinada, principalmente, a consumo animal, alimentação humana e indústria. A maioria dos cultivos está concentrada no seguimento dos pequenos produtores, que se caracterizam pelo uso de poucos insumos no manejo da cultura. Isso se deve, em grande parte, à capacidade que a mandioca tem de se desenvolver e produzir relativamente bem em solos de baixa fertilidade (Carvalho et al, 2007b). Todavia, essa é uma das causas da baixa produtividade brasileira de raízes, observadas nas últimas décadas.

A presença de plantas daninhas em mandiocais tem sido relatada como outro motivo da baixa produção da cultura. De acordo com Silva (2011), a produtividade de raízes da cultura pode ser reduzida em mais de $90 \%$ na ausência do controle do mato. Isso se deve, principalmente, à competição pelos recursos do ambiente, como luz, água e nutrientes. De acordo com diversos pesquisadores, em levantamentos recentes, as espécies de plantas daninhas Bidens pilosa L. e Brachiaria decumbens Stapf são encontradas em grande parte dos mandiocais (Johanns \& Contiero, 2006; Albuquerque et al., 2008; Biffe et al., 2010; Pinotti et al., 2010).

Embora o fósforo não seja extraído em grandes quantidades pela mandioca, maior importância adquire sua aplicação, pois os solos brasileiros em geral, e, em particular, os cultivados com mandioca, normalmente classificados como marginais, são pobres nesse nutriente (Mattos \& Bezerra, 2003). Por esta razão, é grande a resposta da cultura à adubação fosfatada. Em trabalho de Fidalski (1999) foi relatado que dentre os nutrientes N, P e K, a mandioca somente respondeu à adubação fosfatada. A calagem e a adubação nitrogenada e potássica não provocaram incrementos na produção de raízes de mandioca, nesse mesmo trabalho. Segundo Takahashi \& Gonçalo (2005), a resposta da cultura da mandioca à adubação fosfatada é dependente do teor de fósforo no solo.

De acordo com Armstrong et al. (1993), os fertilizantes podem ser usados para alterar as relações de competitividade, de modo a favorecer as espécies cultivadas, pela mudança da comunidade e da densidade de daninhas, desde que as espécies competidoras apresentem respostas diferenciadas à aplicação de nutrientes. Esse fato foi observado por Cralle et al. (2003) que relataram que o crescimento de plantas de trigo foi menos inibido, em solo com deficiência de $\mathrm{P}$, do que o crescimento da espécie daninha Lolium multiflorum.

Contudo, dependendo do manejo, a aplicação de macronutrientes pode beneficiar mais as espécies dani- nhas do que a própria cultura de interesse (Procopio et al., 2005). Um mecanismo, descrito por Patterson (1995), evidencia que muitas plantas daninhas, em áreas com boa disponibilidade de nutrientes, podem acumular concentrações desses elementos acima da necessária para o seu desenvolvimento. Isso indica que não é correto corrigir deficiências nutricionais das culturas, provocadas pela competição com plantas daninhas, simplesmente pelo incremento nas aplicações de fertilizantes (Radosevich et al., 1997).

Visando obter informações para a elaboração de estratégias de fornecimento de nutrientes, que favoreçam as culturas em detrimento das plantas daninhas, neste trabalho objetivou-se avaliar o crescimento da mandioca, do picão preto (B. pilosa $L$.) e da braquiária (B. decumbens Stapf), de acordo com a quantidade de $\mathrm{P}$ fornecida no plantio,

\section{MATERIAL E MÉTODOS}

O experimento foi conduzido em casa de vegetação, com condições controladas de temperatura e umidade. Utilizaram-se amostras de um Argissolo Vermelho distrófico típico, textura argilosa (56\% argila, $6 \%$ silte e $38 \%$ areia). A análise química do solo apresentou $\mathrm{pH}$ (em água) de 6,1; teor de matéria orgânica de $1,0 \mathrm{dag} \mathrm{\textrm {kg } ^ { - 1 }} ; \mathrm{P}, \mathrm{K}, \mathrm{Ca}$, $\mathrm{Mg}, \mathrm{Al}, \mathrm{H}+\mathrm{Al} \mathrm{e} \mathrm{CTC}_{\text {efetiva }}$ de 0,$01 ; 0,06 ; 1,7 ; 0,5 ; 0,01 ; 3,7$ e $2,3 \mathrm{cmol}_{\mathrm{c}} \mathrm{dm}^{-3}$, respectivamente. Para adequação do substrato quanto à nutrição, foram aplicadas doses equivalentes a $300 \mathrm{~kg} \mathrm{ha}^{-1}$ de calcário dolomítico e $50 \mathrm{~kg} \mathrm{ha}^{-1}$ de cloreto de potássio. A adubação nitrogenada foi realizada em cobertura, aos 30 dias após a emergência da cultura, na dose de $40 \mathrm{~kg} \mathrm{ha}^{-1}$ de ureia, previamente dissolvida em água. As irrigações foram realizadas diariamente, de forma a manter os vasos próximos à capacidade de campo.

Adotou-se esquema fatorial $3 \times 4$, sendo o primeiro fator constituído pelas três espécies estudadas: o cultivar de mandioca CACAU UFV e duas espécies de plantas daninhas, Bidens pilosa L. e Brachiaria decumbens Stapf, combinadas com níveis de adubação $(0,80800$ e 4.000 kg ha $^{-1}$ de $\mathrm{P}_{2} \mathrm{O}_{5}$, equivalentes a $0,1,10$ e 50 vezes, respectivamente, a dose de fósforo recomendada por Nogueira \& Gomes, (1999). O experimento foi conduzido em delineamento em blocos casualizados, com cinco repetições. Cada vaso, com capacidade volumétrica de $5 \mathrm{~L}$, contendo solo, representou uma unidade experimental.

As manivas do cultivar Cacau UFV, contendo 5 gemas e com tamanho médio de $15 \mathrm{~cm}$, foram plantadas cinco dias antes das espécies de plantas daninhas, com o intuito de uniformizar a emergência das plantas estudadas. Dez sementes de picão preto e braquiária foram semeadas, por vaso, para garantir a germinação e o de- 
senvolvimento de uma planta em condições de ser avaliada. $\mathrm{O}$ experimento foi composto pela mesma densidade de plantas daninhas e plantas de mandioca (uma planta por vaso).

O período experimental foi de 75 dias após a emergência da mandioca e das plantas daninhas. Esse intervalo foi estabelecido com intuito de coincidir com o período crítico de prevenção da interferência (PCPI) de espécies infestantes na cultura da mandioca, que pode ser estendido até 100 dias após emergência da cultura da mandioca (Silva, 2011).

Ao término desse período, procedeu-se à retirada das plantas de mandioca e das daninhas, separando-as em raízes, caules e folhas, para determinação da massa da matéria fresca e seca. Para a espécie de $B$. decumbens Stapf, os valores para folha e caule representam, respectivamente, folha mais bainha e colmo. Para determinação da área foliar, as folhas de todas as plantas daninhas e da mandioca, depois de separadas, foram escaneadas e digitalizadas para o software Determinador Digital de Áreas (DAA) (Ferreira et al., 2008). Também foram determinados a altura das plantas, o volume de raízes e o número de folhas na ocasião da coleta. Posteriormente, o material vegetal foi lavado em água destilada e secado em estufa, com circulação forçada de ar, a $70^{\circ} \mathrm{C}$, até peso constante. A determinação da massa das matérias fresca e seca foi realizada em balança eletrônica.

Os dados obtidos foram submetidos à análise de variância pelo teste $\mathrm{F}$, ao nível de $5 \%$ de probabilidade. Como o fator quantitativo foi significativo para todas as variáveis, optou-se pelo uso de regressão linear e não linear. As escolhas do modelo foram baseadas na significância dos coeficientes, no coeficiente de determinação e no comportamento biológico do fenômeno.

\section{RESULTADOS E DISCUSSÃO}

A altura das plantas (ALT) estudadas foi aumentada pelas doses de fósforo (Figura 1a). A mandioca mostrouse a espécie menos responsiva em relação ao acréscimo de doses. Já Bidens pilosa $L$. e B. decumbens Stapf obtiveram acentuado incremento da variável até as doses 80 e $800 \mathrm{~kg} \mathrm{ha}^{-1}$, seguido de ganhos menos expressivos para incrementos a partir desta dose .

Em situação de competição por luz, a mandioca seria menos beneficiada pelo aumento da disponibilidade de fósforo, em relação a Bidens pilosa L., pois essa espécie mostrou maior ganho de ALT (Figura 1a). No entanto, para B. decumbens Stapf, Biffe et. al., (2010), observaram que o índice de importância relativa dessa planta daninha foi reduzido, à medida que foi sombreada pela mandioca, sendo esta uma estratégia interessante para plantas de mandioca, quando em competição com essa espécie.
As plantas daninhas Bidens pilosa L. e B. decumbens Stapf apresentaram maior volume de raízes (VRZ) que a mandioca, com o aumento das doses de fósforo (Figura 1b). De acordo com Carvalho et al. (2007a), o maior desenvolvimento de raízes dá-se nos períodos iniciais do ciclo de desenvolvimento das plantas daninhas, fazendo que ocorra aumento no contato dos nutrientes, por interceptação radicular, levando ao rápido acúmulo destes pelas raízes e, consequentemente, menor disponibilidade para a cultura (Carvalho et al., 2007a).

Foi observado aumento do número de folhas (NF) das plantas estudadas, à medida que se aumentou a dose de fósforo (Figura 1c). O incremento dessa variável para Bidens pilosa $\mathrm{L}$., foi maior que para as demais espécies. No entanto, não se observou aumento de sua área foliar (AF), ou seja, produziu mais folhas de menor tamanho (Figura 1d). Para a mandioca constatou-se resposta linear da AF ao aumento de P. Essa característica, juntamente com o acúmulo de matéria seca da parte aérea, proporcionaria a esta cultura a formação de um dossel denso, que, em condição de campo, reduziria a interferência inicial imposta pelas espécies infestantes.

As massas de matéria fresca de folha (MFF) e de caule (MFC) da mandioca apresentaram incrementos lineares com o aumento das doses de fósforo, evidenciando a estratégia da planta na formação da parte aérea, na fase inicial do crescimento. Esse maior crescimento da parte aérea contribui para o aumento do tecido fotossintético e, futuramente maior acúmulo de carboidratos para as raízes, aumentando a produção final da cultura (Viana et al., 2001). Para a MFF, a Bidens pilosa L. e a B. decumbens Stapf portaram-se de maneira semelhante, com respostas positivas quando aplicadas as doses de 80 e de $800 \mathrm{~kg} \mathrm{ha}^{-1} \mathrm{de}$ $\mathrm{P}_{2} \mathrm{O}_{5}$, sem respostas expressivas com a elevação da dose até $4000 \mathrm{~kg} \mathrm{ha}^{-1}$ de $\mathrm{P}_{2} \mathrm{O}_{5}$. Todavia, a resposta da Bidens pilosa $\mathrm{L}$. em termos de MFC foi semelhante à observada para a mandioca, corroborando a resposta constatada para a ALT desta espécie.

Em relação à massa de matéria fresca de raiz (MFR), a planta de mandioca foi a espécie menos influenciada pelo aumento de doses, comportando-se de maneira linear, com pouca diferença entre tratamentos (Figura 2c). Bidens pilosa $\mathrm{L}$. sofreu forte influência das doses de 80 e de 800 $\mathrm{kg} \mathrm{ha}^{-1}$ de $\mathrm{P}_{2} \mathrm{O}_{5 . .}$ com pouca diferença entre as doses de 800 e de $4000 \mathrm{~kg} \mathrm{ha}^{-1}$ de $\mathrm{P}_{2} \mathrm{O}_{5}$. A espécie mais responsiva foi $B$. decumbens Stapf com comportamento linear e maiores valores de produção da variável.

A planta de mandioca apresentou uma tendência crescente, com o aumento das doses de fósforo para a massa de matéria fresca total (MFT) e, de maneira semelhante à B. decumbens Stapf, foi bastante responsiva, embora com valores mais acentuados (Figura 2d). Já Bidens pilosa $\mathrm{L}$. mostrou respostas significativas até a dose de $800 \mathrm{~kg}$ ha- 
${ }^{1}$ de $\mathrm{P}_{2} \mathrm{O}_{5}$ com menores ganhos quando submetida com a elevação da dose até $4000 \mathrm{~kg} \mathrm{ha}^{-1}$ de $\mathrm{P}_{2} \mathrm{O}_{5}$.

As massas de matéria seca de caule (MSC) e de folha (MSF) da planta de mandioca portaram-se linearmente, com o aumento das doses de fósforo, sendo a espécie com os maiores valores. Bidens pilosa L. e B. decumbens Stapf apresentaram incrementos consideráveis de MSC nas doses de 80 e de $800 \mathrm{~kg} \mathrm{ha}^{-1}$ de $\mathrm{P}_{2} \mathrm{O}_{5}$, com ganhos menos expressivos com a elevação das doses até $4000 \mathrm{~kg} \mathrm{ha}^{-1} \mathrm{de}$ $\mathrm{P}_{2} \mathrm{O}_{5} \mathrm{O}$ crescimento rápido da parte aérea de uma planta acarreta maior poder competitivo. Corrêa \& Haag (1993),

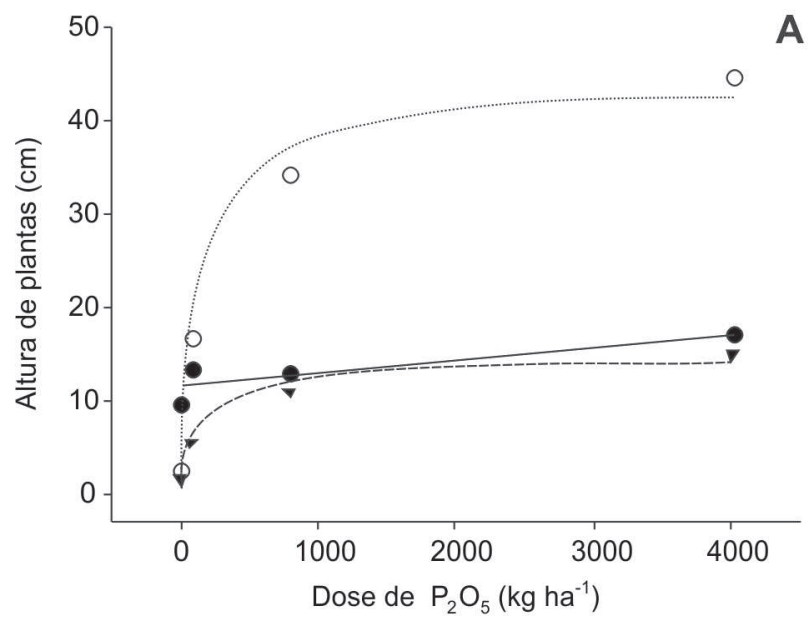

A
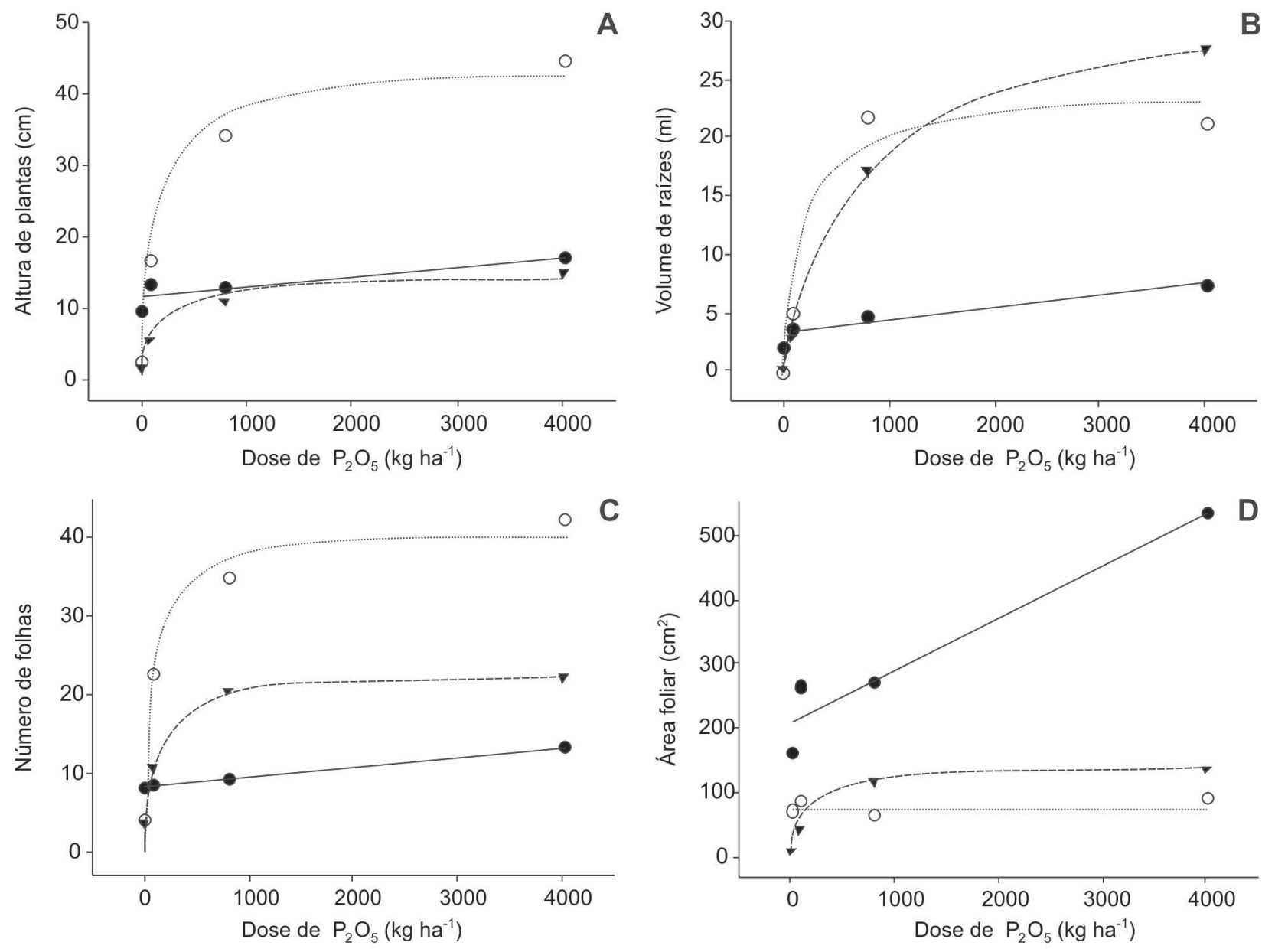

- Mandioca $\quad$ - ……….... Bidens pilosa L.

\begin{tabular}{|c|c|c|c|c|}
\hline Variável & \multicolumn{2}{|l|}{ Altura de plantas $(\mathrm{cm})$} & \multicolumn{2}{|l|}{ Volume de raízes $(\mathrm{ml})$} \\
\hline Espécie & Equação ajustada & $\mathrm{R}^{2}$ & Equação ajustada & $\mathrm{R}^{2}$ \\
\hline Mandioca & $\hat{\mathrm{Y}}=11,6071+0,0014 \mathrm{x}$ & 0,88 & $\hat{\mathrm{Y}}=3,1117+0,0011 \mathrm{x}$ & 0,94 \\
\hline Bidens pilosa $L$. & $\hat{\hat{Y}}=44,0504 x /(146,2784+x)$ & 0,99 & $\hat{\hat{Y}}=24,2172 x /(205,9331+x)$ & 0,99 \\
\hline \multirow[t]{2}{*}{ B. decumbens Stapf } & $\hat{\mathrm{Y}}=14,6330 \mathrm{x} /(157,2819+\mathrm{x})$ & 0,97 & $\hat{Y}=32,7890 x /(744,8612+x)$ & 0,99 \\
\hline & \multicolumn{2}{|l|}{ Número de folhas } & \multicolumn{2}{|l|}{ Área foliar $\left(\mathrm{cm}^{2}\right)$} \\
\hline Mandioca & $\hat{\mathrm{Y}}=8,4198+0,0013 \mathrm{x}$ & 0,99 & $\hat{\mathrm{Y}}=210,4252+0,0818 \mathrm{x}$ & 0,97 \\
\hline Bidens pilosa L. L. & $\hat{\hat{Y}}=40,8518 x /(66,1279+x)$ & 0,98 & $\hat{\mathrm{Y}}=81,3000$ & \\
\hline B. decumbens Stapf & $\hat{\mathrm{Y}}=22,7653 \mathrm{x} /(88,1973+\mathrm{x})$ & 0,97 & $\hat{\hat{Y}}=144,1398 x /(176,7936+x)$ & 0,99 \\
\hline
\end{tabular}

Figura 1. Altura de plantas (A), volume de folhas (B), número de folhas (C) e área foliar (D) de mandioca (cultivar CACAU-UFV), Bidens pilosa L .e Brachiaria decumbens Stapf em função das doses de fósforo ( $\mathrm{kg} \mathrm{ha}^{-1} \mathrm{de}_{2} \mathrm{O}_{5}$ ) aplicadas em um Argissolo Vermelho distrófico típico, textura argilosa. 
A massa de matéria seca de raiz (MSR) da planta de mandioca foi crescente com os aumentos das doses, mas com pouca diferença entre tratamentos, como pode ser observado pelo baixo valor do coeficiente angular da regressão ajustada (Figura 3c). Já para a Bidens pilosa L., constataram-se maiores respostas na MSR para as doses de 80 e de $800 \mathrm{~kg} \mathrm{ha}^{-1}$ de $\mathrm{P}_{2} \mathrm{O}_{5}$, não apresentando diferença com o aumento para a última dosagem. Observaram-se grandes incrementos de MSR para os aumentos de dosagens, em $B$. decumbens Stapf, com os maiores valores entre as espécies em estudo. Bianco et al. (2005), estudando o cres-

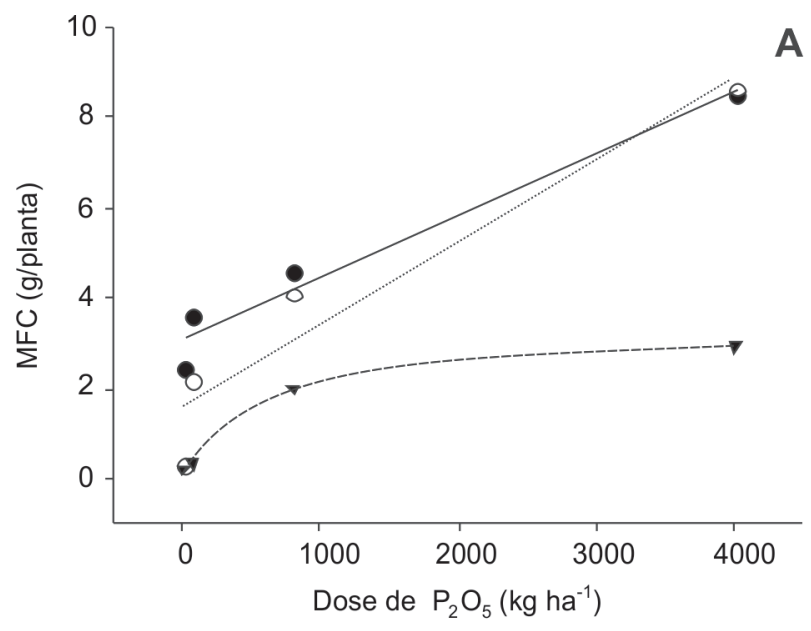

A

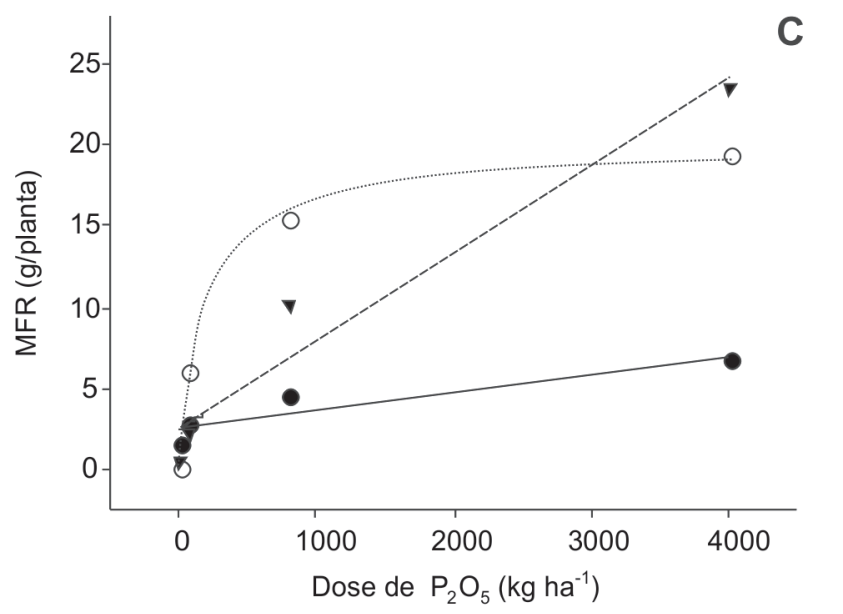

- Mandioca $\quad \bigcirc$................. Bidens pilosa $\mathrm{L}$. cimento e a nutrição da espécie $B$. decumbens, observaram um maior incremento inicial na alocação de matéria seca no sistema radicular, visando a melhor fixação da planta no substrato, e rápido acúmulo de nutrientes pelas raízes.

Os incrementos da massa da matéria seca total (MST) das espécies mandioca e $B$. decumbens Stapf enquadraram-se no modelo linear, com comportamento e valores mais acentuados para a segunda espécie. No entanto, Bidens pilosa $\mathrm{L}$. respondeu às doses de $80 \mathrm{e}$ de $800 \mathrm{~kg} \mathrm{ha}^{-1} \mathrm{de}_{2} \mathrm{O}_{5}$, sem mudanças significativas com o aumento para a dose de $4000 \mathrm{~kg} \mathrm{ha}^{-1}$ de $\mathrm{P}_{2} \mathrm{O}_{5}$.
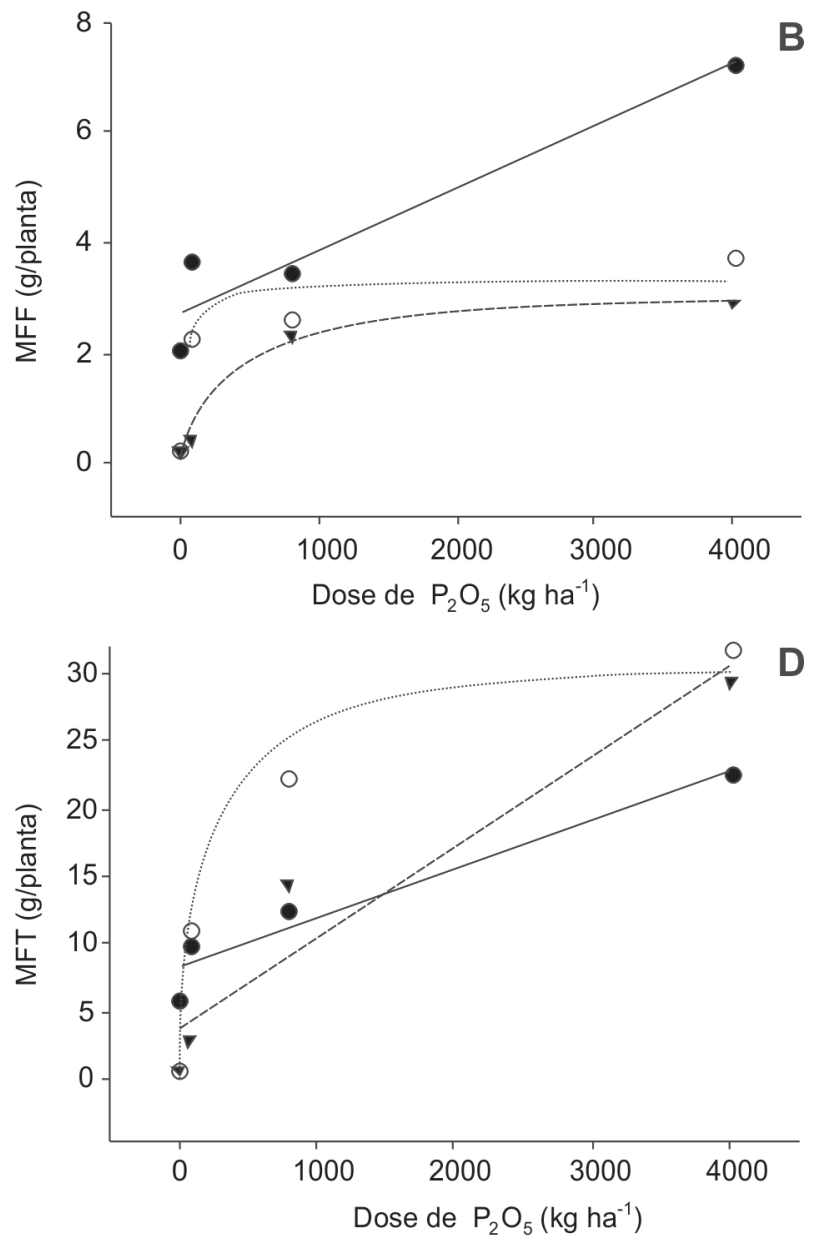

$\nabla$-------- Brachiaria decumbens Stapf

\begin{tabular}{|c|c|c|c|c|}
\hline Variável & \multicolumn{2}{|c|}{ Matéria fresca do caule (g/planta) } & \multicolumn{2}{|c|}{ Matéria fresca da folha ( $\mathrm{g} / \mathrm{planta})$} \\
\hline Espécie & Equação ajustada & $\mathrm{R}^{2}$ & Equação ajustada & $\mathrm{R}^{2}$ \\
\hline Mandioca & $\hat{\mathrm{Y}}=3,0978+0,0014 \mathrm{x}$ & 0,98 & $2,7446+0,0011 x$ & 0,96 \\
\hline Bidens pilosa $L$. & $\hat{\mathrm{Y}}=1,5733+0,0018 \mathrm{x}$ & 0,98 & $\hat{Y}=3,3426 x /(40,8748+x)$ & 0,96 \\
\hline \multirow[t]{2}{*}{ B. decumbens Stapf } & $\hat{\mathrm{Y}}=3,3691 \mathrm{x} /(563,0222+\mathrm{x})$ & 0,99 & $\hat{\mathrm{Y}}=3,2562 \mathrm{x} /(381,1203+\mathrm{x})$ & 0,99 \\
\hline & \multicolumn{2}{|c|}{ Matéria fresca de raízes (g/planta) } & \multicolumn{2}{|c|}{ Matéria fresca total (g/planta) } \\
\hline Mandioca & $\hat{Y}=2,5918+0,0011 x$ & 0,92 & $\hat{Y}=8,4342+0,0036 x$ & 0,97 \\
\hline Bidens pilosa L. L. & $\hat{Y}=20,0033 x /(197,9002+x)$ & 0,99 & $\hat{Y}=31,2611 x /(189,9646+x)$ & 0,99 \\
\hline B. decumbens Stapf & $\hat{\mathrm{Y}}=2,4226+0,0054 \mathrm{x}$ & 0,98 & $\hat{\mathrm{Y}}=3,7825+0,0067 \mathrm{x}$ & 0,96 \\
\hline
\end{tabular}

Figura 2. Matéria fresca de caule (A), folha (B), raízes (C) e total (D) de plantas de mandioca (cultivar CACAU-UFV), Bidens pilosa L.e Brachiaria decumbens Stapf em função das doses de fósforo $\left(\mathrm{kg} \mathrm{ha}^{-1}\right.$ de $\left.\mathrm{P}_{2} \mathrm{O}_{5}\right)$ aplicadas em um Argissolo Vermelho distrófico típico, textura argilosa.

Rev. Ceres, Viçosa, v. 59, n.5, p. 716-722, set/out, 2012 
A competição entre plantas daninhas e culturas é um fator crítico para o desenvolvimento da cultura, quando a espécie daninha se estabelece junto ou primeiro que a cultura (Radosevich et al., 1996). A planta que cobre o solo rapidamente vence a competição, por impedir o acesso da concorrente ao fator luz. O mesmo pode ser dito com relação ao sistema radicular e à absorção de nutrientes. Observa-se que o aumento da dose de $\mathrm{P}_{2} \mathrm{O}_{5}$ aplicada estimulou, principalmente, o incremento da parte aérea da mandioca e da Bidens pilosa L. e de raízes da B. decumbens Stapf.
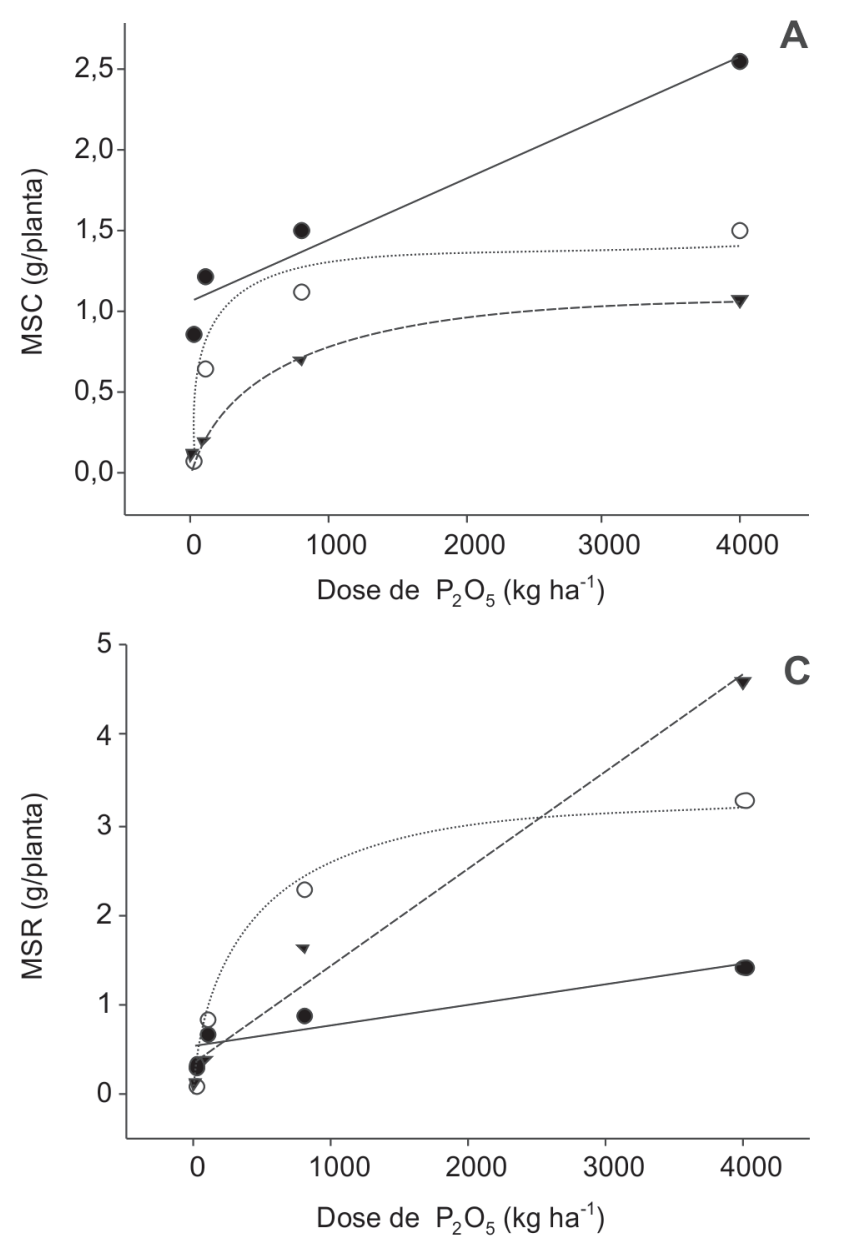

- Mandioca $\quad \bigcirc$-.............. Bidens pilosa L.
Outro fator importante é a resposta das diferentes espécies estudadas ao aumento das doses de fósforo. Enquanto a mandioca apresentou respostas lineares a todas variáveis avaliadas, o crescimento das plantas daninhas tendeu a ser maior em baixas doses de fósforo. Neste caso, a adubação em área total tende a contribuir para o maior crescimento das plantas daninhas do que para o da mandioca. Isto, associado à arquitetura da copa, espaçamento de cultivo e lento crescimento inicial da mandioca, contribui mais ainda para possíveis reduções da produção (Silva, 2011).
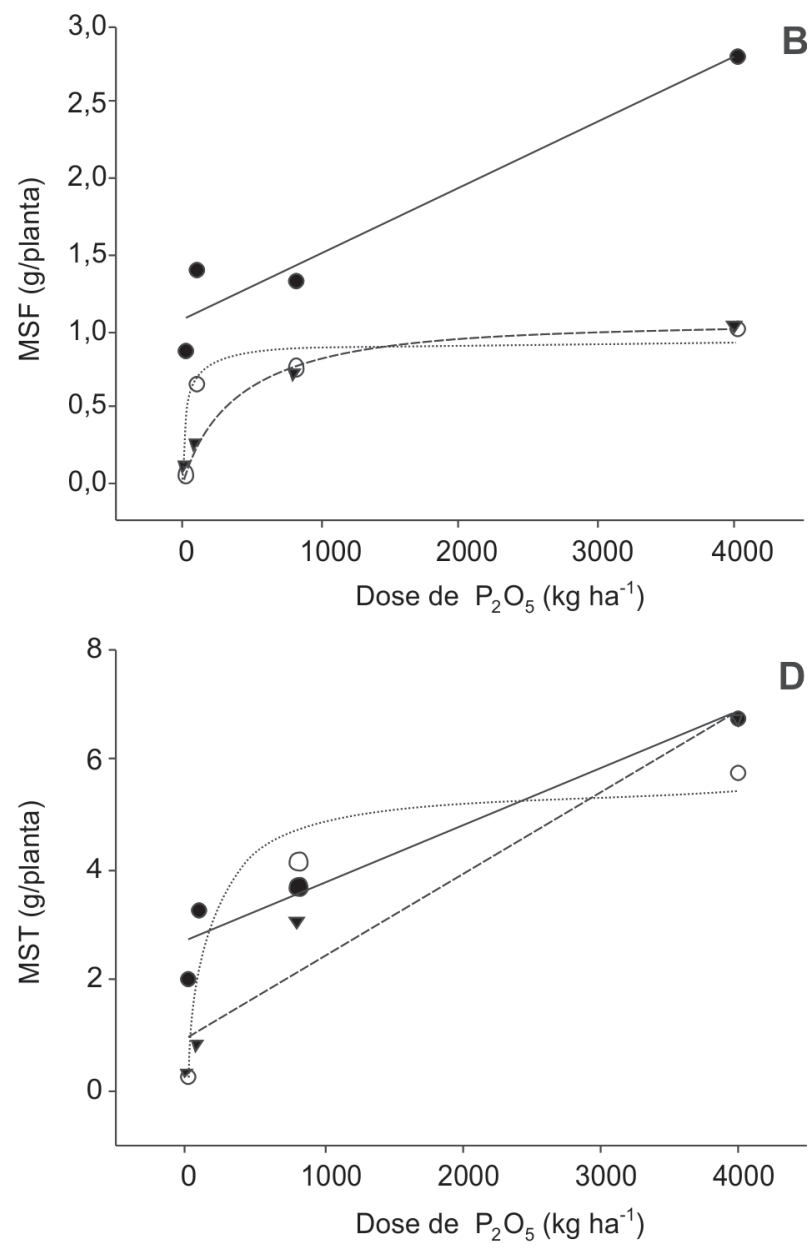

$\nabla$------- Brachiaria decumbens Stapf

\begin{tabular}{clrlr}
\hline Variável & \multicolumn{2}{c}{ Matéria seca do caule (g/planta) } & \multicolumn{2}{c}{ Matéria seca da folha (g/planta) } \\
\hline Espécie & \multicolumn{2}{c}{ Equação ajustada } & $\mathrm{R}^{2}$ & \multicolumn{2}{c}{ Equação ajustada } & $\mathrm{R}^{2}$ \\
\hline Mandioca & $\hat{\mathrm{Y}}=1,0840+0,0004 \mathrm{x}$ & 0,98 & $\hat{\mathrm{Y}}=1,0890+0,0004 \mathrm{x}$ & 0,97 \\
Bidens pilosa $L$. & $\hat{\mathrm{Y}}=1,4442 \mathrm{x} /(105,3254+\mathrm{x})$ & 0,98 & $\hat{\mathrm{Y}}=0,9273 \mathrm{x} /(35,6230+\mathrm{x})$ & 0,97 \\
B. decumbens Stapf & $\hat{\mathrm{Y}}=1,2024 \mathrm{x} /(504,0603+\mathrm{x})$ & 0,99 & $\hat{\mathrm{Y}}=1,1036 \mathrm{x} /(349,791312+\mathrm{x})$ & 0,98 \\
\hline & Matéria seca de raízes (g/planta) & \multicolumn{2}{c}{ Matéria seca total (g/planta $)$} \\
\hline Mandioca & $\hat{\mathrm{Y}}=0,5428+0,0002 \mathrm{x}$ & 0,93 & $\hat{\mathrm{Y}}=2,7157+0,0010 \mathrm{x}$ & 0,97 \\
Bidens pilosa L. L. & $\hat{\mathrm{Y}}=3,4633 \mathrm{x} /(336,0118+\mathrm{x})$ & 0,99 & $\hat{\mathrm{Y}}=5,6024 \mathrm{x} /(142,6635+\mathrm{x})$ & 0,98 \\
B. decumbens Stapf & $\hat{\mathrm{Y}}=0,3631+0,0011 \mathrm{x}$ & 0,99 & $\hat{\mathrm{Y}}=0,9149+0,0015 \mathrm{x}$ & 0,97 \\
\hline
\end{tabular}

Figura 3. Matéria seca de caule (A), folha (B), raízes (C) e total (D) de plantas de mandioca (cultivar CACAU-UFV), Bidens pilosa L.e Brachiaria decumbens Stapf em função das doses de fósforo $\left(\mathrm{kg} \mathrm{ha}^{-1} \mathrm{de}_{2} \mathrm{O}_{5}\right)$ aplicadas em um Argissolo Vermelho distrófico típico, textura argilosa. 


\section{CONCLUSÕES}

A aplicação do fertilizante fosfatado promoveu maior crescimento das espécies avaliadas; a mandioca apresentou maior crescimento da parte aérea com o aumento da disponibilidade de fósforo.

De maneira geral, as plantas daninhas apresentaram maiores respostas às menores doses de fósforo.

\section{AGRADECIMENTOS}

Ao Conselho Nacional de Desenvolvimento Científico e Tecnológico (CNPq), à Fundação de Amparo à Pesquisa do Estado de Minas Gerais (FAPEMIG) e à Coordenação de Aperfeiçoamento de Pessoal de Nível Superior (CAPES), pelo apoio financeiro na execução deste trabalho.

\section{REFERÊNCIAS}

Albuquerque JAA, Sediyama T, Silva AA, Carneiro JES, Cecon PR \& Alves JMA (2008) Interferência de plantas daninhas sobre a produtividade da mandioca (Manihot esculenta). Planta Daninha, 26:279-289.

Armstrong RD, Brown RF \& Helyar KR (1993) The use of nitrogen, phosphorus and lime to limit the competitive ability of Aristida armata in the establishment phase. Australian Journal of Agricultural Research, 44:167-178.

Bianco S, Tonhao MAR \& Pitelli RA (2005) Crescimento e nutrição mineral de capim-braquiária. Planta Daninha, 23:423-428.

Biffe DF, Constantin J, Oliveira Jr RS, Franchini LHM, Rios FA, Blainski E, Arantes JGZ, Alonso DG \& Cavalieri SD (2010) Período de interferência de plantas daninhas em mandioca (Manihot esculenta) no noroeste do Paraná. Planta Daninha, 28:471-478.

Carvalho LB, Bianco S, Pitelli RA \& Bianco MS (2007a) Estudo comparativo do acúmulo de massa seca e macronutrientes por plantas de milho var. BR-106 e Brachiaria plantaginea. Planta Daninha, 25:293-301.

Carvalho FM, Viana AES, Matsumoto SN, Rebouças TNH, Cardoso CEL \& Gomes IR (2007b) Manejo do solo em cultivo com mandioca em treze municípios da região sudeste da Bahia. Ciência e Agrotecnologia, 31:378-384.

Corrêa LA \& Haag HP (1993) Níveis críticos de fósforo para o estabelecimento de gramíneas forrageiras em Latossolo Vermelho Amarelo, álico: II. Experimento de campo. Scientia Agricola, 50:109-116.

Cralle HT, Fojtasek TB, Carson KH, Chandler JM, Miller TD, Senseman SA, Bovey RW \& Stone MJ (2003) Wheat and italian ryegrass (Lolium multiflorum) competition as affected by phosphorus nutrition. Weed Science, 51:425-429.

Ferreira OGL, Rossi FDM \& Andrighetto C (2008) DDA: Software para determinação de área foliar, índice de área foliar e área de olho de lombo. Versão 1.2. Santo Augusto, CD-ROM.

Fidalski J (1999) Respostas da mandioca à adubação NPK e calagem em solos arenosos do noroeste do Paraná. Pesquisa Agropecuária Brasileira, 34:1353-1359.

IBGE (2011) Instituto Brasileiro de Geografia e Estatística. Sétima previsão da safra 2011/2012. Disponível em: <http:// ww w 1.ibge.gov.br/home/presidencia/noticias/ noticia_visualiza.php?id_noticia $=1798 \&$ \&d_pagina $=1>$. Acessado em: 10 de novembro de 2011.
Johanns O \& Contiero $R$ (2006) Efeitos de diferentes períodos de controle e convivência de plantas daninhas com a cultura da mandioca. Revista Ciência Agronômica, 37:326-331.

Mattos PLP \& Bezerra VS (2003) Cultivo de mandioca para o estado do Amapá. Disponível em: <http:// sistemasdeproducao.cnptia.embrapa.br/FontesHTML/Mandioca /mandioca_amapa/adubacao.htm >. Acessado em: 23 de março de 2012 .

Nogueira FD \& Gomes JC (1999) Mandioca. In: Ribeiro AC, Guimarães PTG, Alvarez Viegas VH (Eds.) Recomendações para o uso de corretivos e fertilizantes em Minas Gerais: $5^{\text {a }}$ aproximação. Viçosa, Comissão de Fertilidade do Solo do Estado de Minas Gerais. p.312-313.

Patterson DT (1995) Effects of environmental stress on weed/ crop interactions. Weed Science, 43:483-490.

Pinotti EB, Bicudo SJ, Curcelli F \& Dourado WS (2010) Levantamento florístico de plantas daninhas na cultura da mandioca no município de Pompéia - SP. Revista Raízes e Amidos Tropicais, $6: 120-125$.

Procopio SO, Santos JB, Pires FR, Silva AA \& Mendonça ES (2005) Absorção e utilização do fósforo pelas culturas da soja e do feijão e por plantas daninhas. Revista Brasileira de Ciência do Solo, 29:911-921

Radosevich SR, Holt J \& Ghersa C (1996) Physiological aspects of competition. In: Radosevich SR, Holt J \& Ghersa C (Eds.) Weed ecology: Implication for managements. New York, John Willey \& Sons. p.217-301.

Radosevich SR, Holt J \& Ghersa C (1997) Weed ecology: implications for management. $2^{\mathrm{a} e d . ~ N e w ~ Y o r k, ~ W i l l e y . ~ 589 p . ~}$

Santos JB \& Cury JP (2011) Picão-preto: uma planta daninha especial em solos tropicais. Planta Daninha, 29:1159-1172.

Silva DV, Santos JB, Ferreira EA, Silva AA, França AC \& Sediyama T (2012) Manejo de plantas daninhas na cultura da mandioca. Planta daninha, 30:901-910.

Takahashi M, Gonçalo S (2005) A cultura da mandioca. Paranavaí, PR: Editora Gráfica Olímpica. 116 p.

Viana AES, Sediyama T, Lopes SC, Cecon PR \& Silva AA (2001) Efeito do comprimento e de incisões no córtex da maniva sobre o cultivo da mandioca (Manihot esculenta Crantz). Acta Scientiarum Agronomy, 23:1263-1269. 